\title{
Vibrio anguillarum Suşlarında Çevreyi Algılama Sistemi ve Virülens Faktörlerinin İncelenmesi*
}

\section{Nurdan NURCAN ${ }^{1}$, Ayşegül KUBİLAY ${ }^{1 * *}$, Gülgün BOŞGELMEZ-TINAZ ${ }^{2}$}

${ }^{1}$ Süleyman Demirel Üniversitesi Eğirdir Su Ürünleri Fakültesi, Isparta

2Marmara Üniversitesi Eczacıllk Fakültesi, İstanbul

Geliş : $\quad 10.12 .2015$

Kabul : $\quad 06.04 .2016$

**Sorumlu yazar: aykub@yahoo.com

Basıl1 ISSN: 1300 - 4891E. Dergi ISSN: 1308 - 7517

\section{Özet}

Son yıllarda yapılan araştırmalar, patojenik bakterilerin bir çoğunun virülens faktörlerinin üretimini $N$-açil homoserin lakton (AHL) türevi sinyal molekülleri aracılığ ile kontrol ettiğini ortaya koymuştur. Bu çalışmada Gram negatif bakteriyel bir balık patojeni olan Vibrio anguillarum izolatlarında $N$-açil homoserin lakton türevi sinyal moleküllerinin üretimi, Chromobacterium violaceum CV026 ve Agrobacterium tumafeciens NT1 biyosensör suşları kullanılarak araştırılmıştır. Pseudomonas aeruginosa PAO1 suşu pozitif kontrol olarak kullanılmıştır. Çalışma sonucunda V. anguillarum suşlarının, C. violaceum CV026 suşu kullanılarak yapılan testlerde negatif sonuç vermesine karşın, A. tumafeciens NT1 kullanılarak yapılan testlerde, pozitif sonuçlar verdiği saptanmıştır. Ayrıca bu suşların, $V$. anguillarum 'un patojenitesinde önemli rol oynadıkları düşünülen biyofilm oluşumu, pigment üretimi ve proteaz aktivitesi gösterdikleri tespit edilmiştir.

Anahtar kelimeler: $V$. anguillarum, çevreyi algılama sistemi, biyofilm, pigment, proteaz, $N$-açil homoserin lakton

\section{Investigation on Quorum Sensing System and Virulence Factors of Vibrio anguillarum Strains}

\begin{abstract}
In recent years, are reported that virulence factors of many pathogenic bacteria are controlled via acyl homoserine lactone (AHL) signaling molecules. In this study, production of $\mathrm{N}$-acyl homoserine lactone signaling molecules were investigated using Choromobacterium violaceum CV026 and Agrobacterium tumefaciens NT1 biosensor strains in Vibrio anguillarum isolates, Gram negative fish pathogens. Pseudomonas aeruginosa PAO1 strain was used as a positive control. As a result of, it was found that negative results by using $C$. violaceum $\mathrm{CV} 026$ in test, despite positive results using A. tumafeciens NT1 in test of $V$. anguillarum strains. In addition were determined of biofilm formation, production of pigments and protease activity which are thought to play an important role in the pathogenesis in the $V$. anguillarum strains.
\end{abstract}

Keywords: V. anguillarum, quorum sensing system, biofilm, pigment, protease, $N$-acyl homoserine lactones *Bu çalışma, yüksek lisans tezinden özetlenmiştir.

\section{GİRIŞ}

Günümüzde bakterilerin neden olduğu enfeksiyonların tedavisi için en yaygın olarak tercih edilen yöntem antibiyotik kullanımıdır. Ancak gereksiz ve uygunsuz antibiyotik kullanımı antibiyotiklere karşı dirençli bakterilerin ortaya çıkmasına, bu da, kullanılan antibiyotiklerin giderek etkisiz kalması, dolayısıyla hastalıkların tam anlamıyla tedavi edilememesi ve direncin yayılması ile sonuçlanmaktadır. Bu nedenle, "enfeksiyon hastalıkları" hala dünyada en önde gelen ölüm nedenlerinden biridir (Baskın, 2005).Günümüzde hastalık yapan bakterilerin \% 70'in den fazlası klinikte kullanılan mevcut antibiyotiklerden en az birine karşı dirençli hale gelmiştir. Dolayısıyla, yeni 
antimikrobiyal hedeflerin saptanmasına yönelik araştırmalar çok büyük önem kazanmıştır. $\mathrm{Bu}$ hedeflerden bir tanesi bakteriler arası iletişim (quorum sensing) mekanizmasının inhibe edilmesidir. Gram (-) bakteriler birbirleriyle haberleşme amaciyla, açil-homoserin lakton (AHL) türevi sinyal moleküllerini kullanırlar. Bakteriler bu sinyal molekülleri aracıllğıyla yeterli çoğunluğa ulaşıp ulaşmadıklarını izlemekte ve yeter çoğunluğa ulaştıkları anda da virülens faktörlerinin üretimi gibi kritik gen ekspresyonlarını tetiklemektedirler. Hücreler arası iletişimi sağlayan bu haberleşme sistemi quorum sensing (çevreyi algılama) olarak adlandırılır (Boşgelmez-Tınaz , 2003; Chu vd., 2015). Bu olay bakteriye kendi hücre populasyon yoğunluğunu izleme ve buna bağlı olarak davranışlarını düzenlenme olanağı verir. Böylelikle, konakta enfeksiyon oluşturabilecek yeter çoğunluğa ulaşıncaya kadar bağışıklık sistemi tarafından patojen bakterinin fark edilmemesi sağlanarak başarılı bir enfeksiyon süreci oluşturulur (Bosgelmez-Tınaz, 2013). İlk defa Vibrio fisheri'de tanımlanmış olan bu bakteriyel iletişim sisteminin daha sonra bu bakteri ile sinırlı olmadığı Erwinia carotovora, Yersinia enterocolitica, A. tumefaciens ve Pseudomonas aeruginosa gibi bir çok insan, hayvan ve bitki patojeni tarafindan yaygın olarak kullanıldığı keşfedilmiştir (Milton vd., 1997). Gram negatif bakteriler birbirleriyle haberleşme amacıyla, açil-homoserin lakton (AHLs) moleküllerini kullandıkları bilinmektedir (Boşgelmez-Tınaz, 2003).

$V$. anguillarum Gram negatif bakteriyel bir balık patojenidir. Balıklarda hemorajik septisemiye neden olan vibriozis hastalığının etkenidir (Milton vd., 1997).

Daha önce yapılan çalışmalar $V$. anguillarum'da çevreyi algılama sistemi ve virülens arasında doğrudan bir bağlantı olmadığını göstermiştir (Milton vd., 2001, Purohit, 2013). Ancak, ilginç bir şekilde bir çevreyi algılama sistemi inhibitörü olan furanon C30'un gökkuşağı alabalıklarında $V$. anguillarum'un neden olduğu vibriozis'den ölümleri azalttığı gözlenmiş̧ir (Rasch vd,. 2004; Bruhn vd., 2005). Bakterilerde bu sistemin ve virülens faktörlerinin üretim mekanizmalarının çalışılması, patojen bakterilerin neden olduğu hastalıkların önüne geçilmesi açısından büyük önem taşımaktadır. $\mathrm{Bu}$ nedenle, bu çalışmada, $V$. anguillarum izolatlarında çevreyi algılama sistemi ve virulens faktörlerinin incelenmesi amaçlanmıştır. Bu kapsamda; $V$. anguillarum'un ürettiği $N$-açil homoserin lakton (AHL) sinyal moleküllerinin tespiti ve çevreyi algılama sisteminin etkisi altında olan virülens faktörlerinden özellikle biyofilm oluşumu, pigment ve proteaz üretimleri incelenmiştir.

\section{MATERYAL ve YÖNTEM}

Araştırmada S.D.Ü. Eğirdir Su Ürünleri Fakültesi mikroorganizma koleksiyonu içinden alınan 5 adet $V$. anguillarum suşu kullanılmıştır. Pozitif kontrol olarak $P$. aeruginosa PAO1 suşu, AHL sinyal moleküllerinin tespiti için kullanılan $C$. violaceum CV026 ve $A$. tumefaciens NT1 biyosensör suşları S.D.Ü. Fen Edebiyat Fakültesi Biyoloji Bölümü'nden temin edilmiştir.

\section{AHL moleküllerinin tespiti}

AHL sinyal moleküllerinin tespiti, $C$. violaceum CV026 ve A. tumefaciens NT1 biyosensör suşları kullanılarak gerçekleştirilmiştir. Açil yan zincirinde 4-8 karbona sahip AHL moleküllerinin tespiti için, C. violaceum CV026 suşu kullanılmıştır. Ortamdaki mevcut AHL molekülleri, $C$. violaceum $\mathrm{CV} 026$ suşunda mor bir pigment olan viyolasinin üretimini uyarır (McClean vd., 1997). Diğer bir biyosensör olarak, pZLR4 plazmiti taşıyan 
A. tumefaciens NT1suşu kullanılmıştır (Shaw vd., 1997; Cha vd., 1998; Ravn vd., 2001). A. tumefaciens NT1 biyosensör suşu, ortamda X-Gal (5-Bromo-4-kloro-3-indolil- $\beta$-Dgalaktopiranosid) varlığında, $N$-açil yan zincirinde 6-12 karbona sahip AHL molekülünün uyarmasıyla yeşil pigment meydana getirir (Bruhn vd., 2005; Ulusoy, 2007; Myszka ve Czaczyk 2012; Purohit, 2013).

\section{AHL moleküllerinin tespiti için çapraz doğrulama testi}

Çalışılan suşlarda AHL moleküllerinin üretimi, her iki biyosensör suş (CV026 ve NT1) ile besiyeri üzerinde paralel çizilerek test edilmiştir. Sonuçlar P. aeruginosa PAO1 suşuyla karşılaştırılarak değerlendirilmiştir (Ulusoy, 2007; Mohaddam vd., 2014).

\section{Biyofilm testi}

Biyofilm oluşumu O'Toole ve Kolter'in (1998) tanımladığı metoda göre gerçekleştirilmiştir. V. anguillarum suşları LB besiyerinde (\%3 $\mathrm{NaCl}$ eklenmiş) (LBS) 16 saat üretilmiştir. İnkübasyondan sonra bakteri yoğunluğu OD 600'de 0,8'e ayarlanmıştır. Bakteri kültürü 1/100'lük steril LBS ortamı ile sulandırılmıştır. Sulandırılan kültürler düz tabanlı 96 çukurlu mikroplakalara $100 \mu \mathrm{l}$ olarak ilave edilmiş ve $30^{\circ} \mathrm{C}$ 'de 24 saat inkübe edilmiştir. İnkübasyonu takiben mikroplakalar distile su ile y1kanmış ve \%1'lik kristal viyole ile $15 \mathrm{dk}$ süresince boyanmıştır. Daha sonra boya dökülerek fazlası saf su ile yıkanmıştır. $200 \mu \mathrm{L} \% 95$ etanol eklenerek absorbans değerleri ELISA okuyucuda 490 nm'de okunarak değerlendirilmiştir (Ye vd., 2008; Deepa vd., 2014).

\section{Pigment testi}

Test edilecek $V$. anguillarum suşları \% $1 \mathrm{NaCl}$ içeren $10 \mathrm{ml} \mathrm{LBS}$ besiyerinde $25^{\circ} \mathrm{C}$ ' de 24 saat üretilmiştir. İnkübe edilen bakteri kültürleri OD600'de 0.05'e ayarlanmıştır. Dilüsyonda LB ve LB içinde 5mM'lık L-Tryosine (Tirozin) içeren ortam kullanılmış ve hazırlanan kültürler $25^{\circ} \mathrm{C}$ 'de karıştırılarak 24 saat inkübe edilmiştir. Çeşitli zaman aralıklarında tirozin içeren ve içermeyen kültürlerden $1 \mathrm{ml}$ örnek alınarak 12000 devirde 2 dksantrifüj edilerek süpernatantı toplanmıştır. Süpernatantlar 96 çukurlu düz tabanlı mikroplakalara100 $\mu 1$ ilave edilerek, her bakteri izolatı için ayrı ayrı çalışılmıştır. Pigment üretimi; 405 nm' de ELISA okuyucusunda optik yoğunluklarının ölçümü ile hesaplanmıştır (Croxatto vd., 2002).

\section{Proteaz testi}

Test edilecek 18 saatlik $V$. anguillarum suşları \% 2 yağsız süt tozu içeren \%1 oranında tuz $(\mathrm{NaCl})$ ilaveli TSA petrilerinin ortasına açılan $3 \mathrm{~mm}$ 'lik çukurlara $20 \mu \mathrm{l}$ ilave edilmiş ve $25^{\circ} \mathrm{C}$ 'de 24 saat inkübasyona bırakılmıştır. İnkübasyon sonucunda bakteri kolonisi etrafındaki saydam zon proteolitik aktivitenin göstergesi olarak kabul edilmiştir (Arda, 1997; Swift vd., 1999; Dong vd., 2005; Ulusoy, 2007). Suşların proteolitik aktiviteleri bakteri kültürü ilave edilen bölgedeki berrak zon çapı ölçülerek kaydedilmiştir.

\section{BULGULAR}

Çalışmada kullanılan V. anguillarum suşlarının (A4, A5, A6, ATCC, ATCC 700183) C. violaceum CV026 ve A. tumefaciens NT1 biyosensör suşları ile yapılan testlerde uzun zincirli bir sinyal molekülü olan $N$-(3-oxodecanoyl)-L-homoserin lakton (ODHL) 
molekülünü üretmelerine karşın, kısa zincirli bir sinyal molekülü olan $N$-hexanoyl-Lhomoserin lakton (C6-HSL) üretmediği gözlenmiştir.

$V$. anguillarum suşlarında ODHL sinyal moleküllerinin varlığının tespiti ile bu moleküllere bağımlı olarak gerçekleşen biyofilm oluşturma, pigment ve proteaz üretimi gibi çevreyi algılama sistemi tarafından kontrol edilen virülens faktörleri de tespit edilmiştir.

Biyosensör Suşlar Aracılığıyla $V$. anguillarum'da N-acyl Homoserin Lakton (AHL) Sinyal Moleküllerinin Tespiti

AHL moleküllerinin üretimi, C. violaceum CV026 ve A. tumafeciens NT1 biyosensör suşları kullanılarak fenotipik olarak araştırılmıştır. Hem uzun zincirli hem de kısa zincirli açil homoserin lakton molekülleri üretebilen $P$. aeruginosa PA01 suşu pozitif kontrol olarak kullanılmıştır. C. violaceum CV026 suşu kullanılarak yapılan testte $V$. anguillarum suşlarının kısa zincirli $N$-hexanoyl-L-homoserine lacton (C6-HSL) sinyal molekülünü üretmediği tespit edilmiştir. C6-HSL sinyal molekülünü üretmeyen $V$. anguillarum suşlarının tamamının A. tumefaciens NT1suşu kullanılarak yapılan testte ise ODHL sinyal molekülünü üretebildikleri saptanmıştır (Şekil 1).

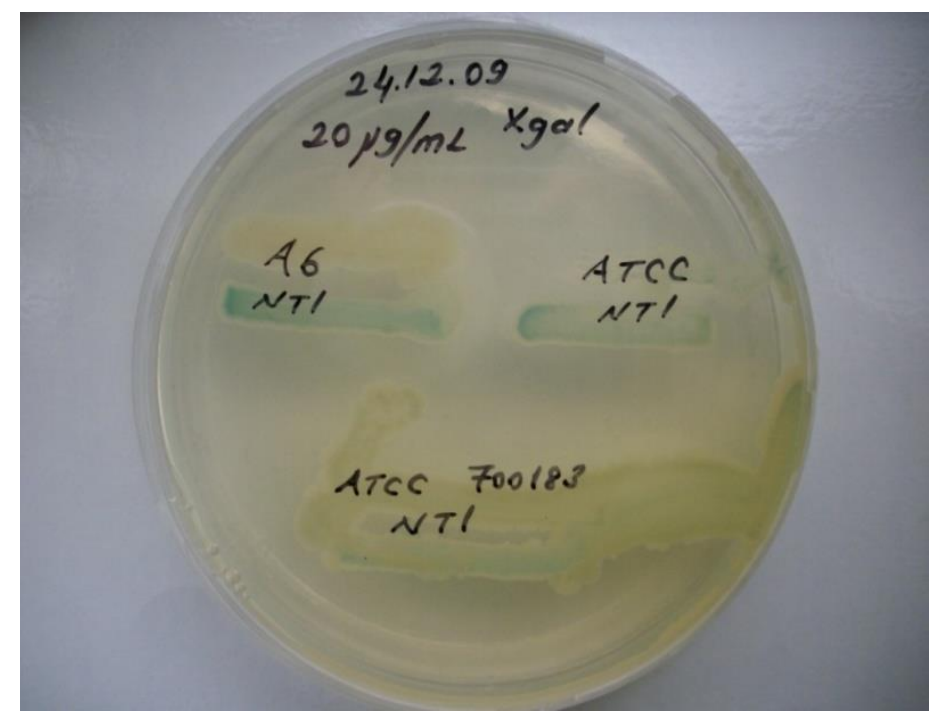

Şekil 1. A. tumefaciens NT1 indikatör suşu kremden yeşile renk değişimiyle $V$. anguillarum'da, ODHL sinyal moleküllerinin varlı̆̆

\section{N-(3-okzodekanoyl)- L-homoserinelactone (ODHL) Sinyal Moleküllerine Bağımlı Virülens Faktörlerinin Üretimi}

V. anguillarum suşları; biyofilm oluşumu, pigment ve proteaz üretimi gibi çevreyi algılama sistemi tarafından kontrol edilen virülens faktörlerinin varlığı bakımından test edilmiştir.

\section{V. anguillarum'da biyofilm testi bulguları}

V. anguillarum suşlarının tümünde (A4, A5, A6, ATCC, ATCC 700183) biyofilm oluşumu tespit edilmiştir (Şekil 2, 3). 


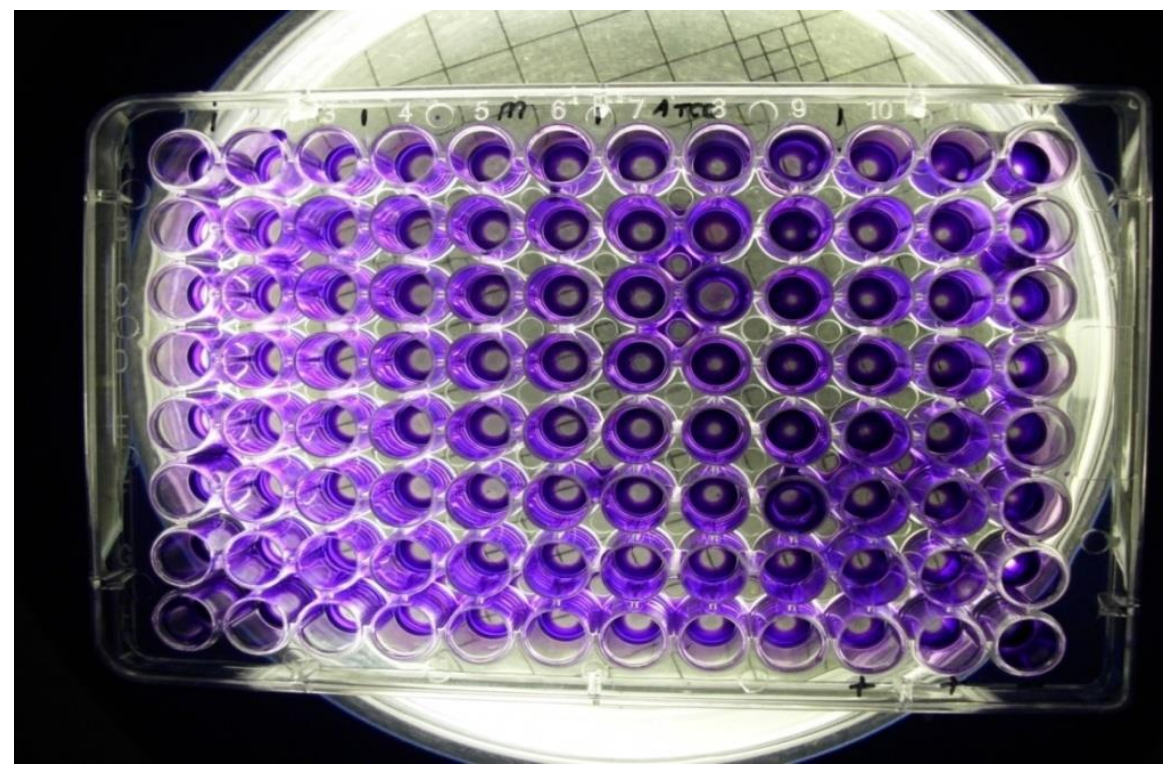

Şekil 2. Kristal viyole ile boyanmış biyofilm

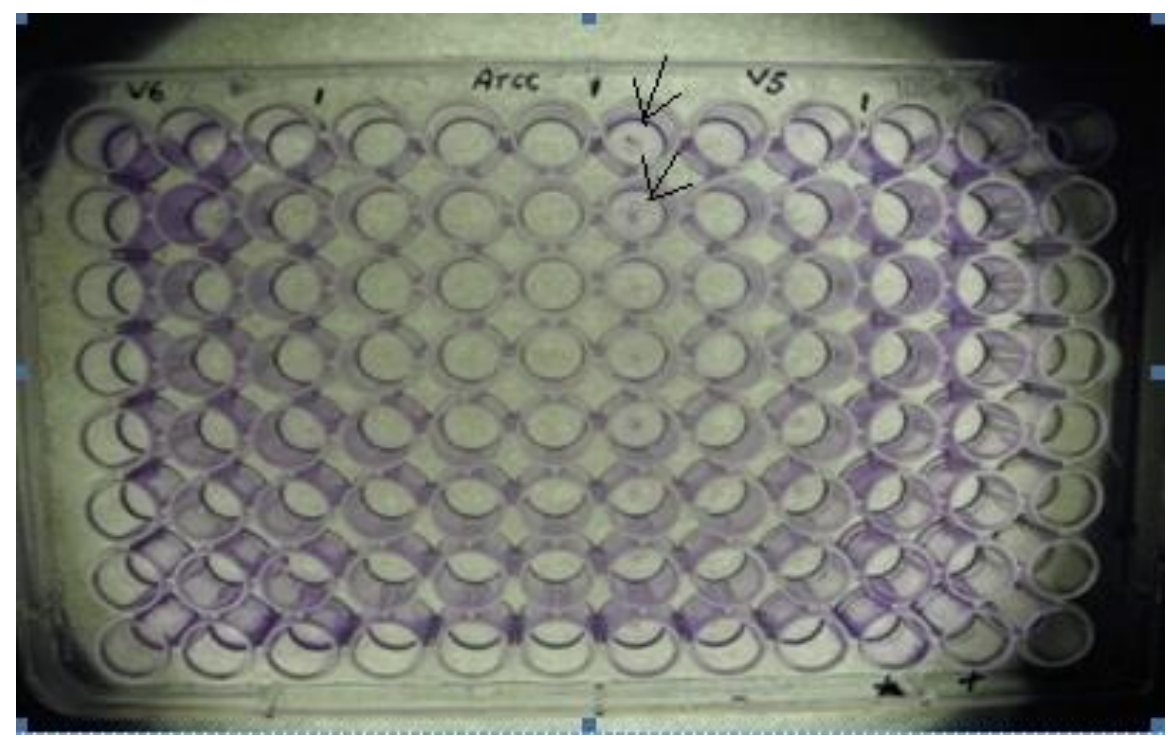

Şekil 3. V. anguillarum suşlarında biyofilm oluşumu

\section{V. anguillarum'da pigment testi bulguları}

V. anguillarum suşlarında pigment üretimi ölçümünün sonuçları incelendiğinde tirozin ilave edildikten sonra suşlarda pigment üretimini tespit etmek amacıyla bakılan optik yoğunluğun 20., 40. ve 50. saatlerde yüksek olduğu belirlenmiştir. Sonuç olarak, çalışılan $V$. anguillarum suşlarının tümünde tirozin varlığının pigment üretimini artırdığı saptanmıştır. 


\section{V. anguillarum'da proteaz testi bulguları}

Proteaz üretimi tespiti amacıyla kontrol şuşu $P$. aeruginosa PAO1 kullanılmıştır.

Virülens faktörlerinden proteaz üretiminin $V$. anguillarum A6 suşunda $18 \mathrm{~mm}$ zon çapıyla en geniş zon çapına sahip olduğu kaydedilmiştir. Kullanılan diğer suşlar da; A5 17 mm (Şekil 4), A4 ve ATCC 70018316 mm ve ATCC 12,3 mm zon çapı ölçülerek, proteaz aktivitesi gösterdiği belirlenmiştir.

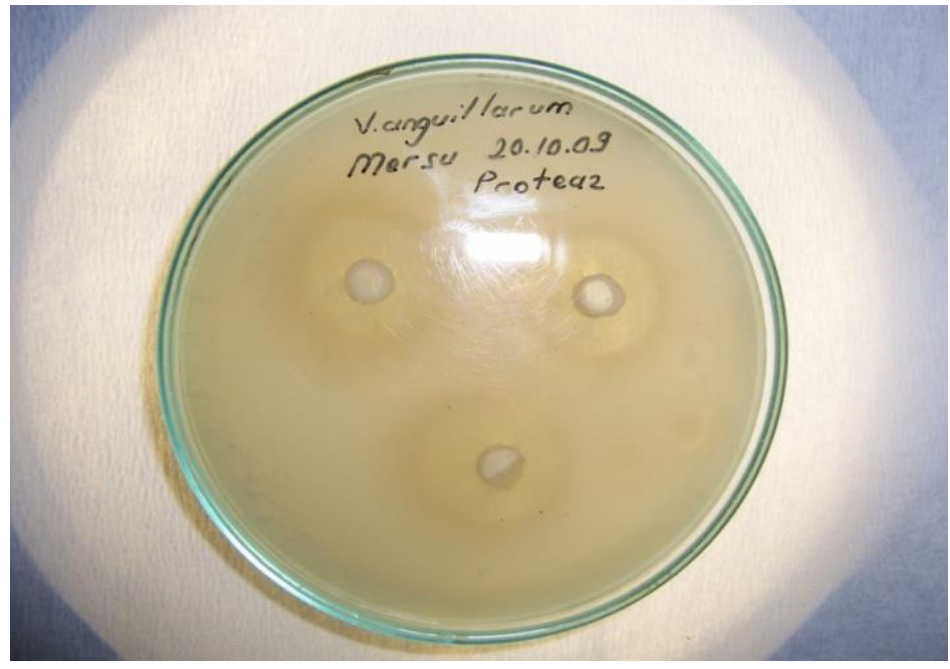

Şekil 4. V. anguilarum'da proteaz aktivitesi

\section{TARTIŞMA ve SONUÇ}

Birçok mikroorganizma sosyal bazı davranışlar sergilemektedir. Üretmiş oldukları sinyal molekülleri aracılığı ile birbirleri ile iletişim kurmakta, belirli bir çoğunluğa ulaşıp ulaşmadıklarını izlemekte ve yeter çoğunluğa ulaştıkları anda da virülens faktörlerinin sentezi gibi kritik gen ekspresyonlarını tetiklemektedir. Böylelikle, konağın bağışıklık sistemini zamanından önce uyarmayarak başarılı bir enfeksiyon süreci oluşturabilmektedirler (Saraçl1, 2006). Patojenik bakterilerin birçoğunun virülens faktörlerinin üretimini AHL türevi sinyal molekülleri aracıllı̆g ile kontrol ettiğinin keşfedilmesi ile çevreyi algılama sistemi antimikrobiyal tedavi için yeni ve cazip bir hedef halini almıştır. $\mathrm{Bu}$ nedenle patojen bakterilerde çevreyi algılama sistemi ve virülens faktörlerinin üretiminin incelenmesi bu patojenlerin yol açtığı hastalıkların önlenmesinde büyük önem taşımaktadır.

Wang 2004'de yaptığ bir çalışmada $V$. anguillarum $N$-(3-oxodecanoyl)-HSL (3-oxoC10-HSL) ve $N$-hexanoyl-L-homoserine lactone (C6-HSL) moleküllerini kullanarak haberleştiklerini bildirmiştir. Bu araştırmada da C. violaceum CV026 suşu kullanılarak yapılan testlerde $V$. anguillarum suşlarının kısa zincirli sinyal molekülünü olan C6-HSL üretmediği tespit edilmiştir. C6-HSLsinyal molekülünü üretmeyen bu suşların tamamının A. tumefaciens NT1 suşu kullanılarak yapılan testte ise uzun zincirli sinyal molekülü 3-oxoC10-HSL üretebildikleri tespit edilmiştir

Daha önceki araştırmalarda, V. anguillarum (Defoirdt, 2005; Milton vd., 1997) suşlarında ODHL(3-oxo-C10-HSL) sinyal moleküllerinin varlığ bildirilmiştir. Yapılan bu çalışmalar ile $V$. anguillarum'da ODHL suşlarındaki sonuçlar benzerlik göstermiştir. 
Balıklarda ciddi virülens oluşturan $V$. anguillarum suşlarının tümünde fenotipik olarak biyofilm oluşumu belirlenmiştir. Biyofilm oluşumunu, V. anguillarum (Croxatto vd., 2002) suşlarında ele almışlardır. Bildirilen bu çalışmalardaki $V$. anguillarum suşlarındaki biyofilm oluşumu araştırmamızda da benzerlik göstermektedir

Croxatto vd. (2002), yaptıkları çalışmayla V. anguillarum suşlarında tirozin ile pigment tespitini belirtmişlerdir. Yaptığımız çalışmada daV. anguillarum suşlarının tamamında tirozinin pigment üretimini artırdığı optik yoğunluklar ölçüldüğünde görülmüştür. Bakterilerde çevreyi algılama yönetimindeki ciddi virülens faktörlerinden biri olan proteaz; $V$. anguillarum'un tüm suşlarında tespit edilmiştir.

En basit yapılı canlılardan biri olarak bilinen bakterilerin sistemleşmiş milyarlarca hücreden oluşan organizmalar olarak balıklarda nasıl hastalık oluşturduğunun özellikle doğal ortamlarda ve yetiştiricilik ünitelerinde nasıl ciddi kayıplara sebep olduğunun cevaplarından birisi de çevreyi algılamadır. Çevreyi algılama bakterilerin düşünerek hareket ettiklerinin de bir göstergesidir. Aralarındaki bakteriyel iletişimin bir nedenle engellenmesi veya kesilmesi balıklar üzerindeki olumsuz etkilerin büyük oranda azaltacaktır. Son yıllarda, su ürünleri yetiştiriciliğinde, iyi bir yönetim için alternatif stratejiler arasında probiyotik, immunostimulant uygulamaları ve aşılar gibi yöntemler başarılı bir şekilde kullanılmaktadır. Ancak bu metotlara alternatif yeni metotlara da gereksinim vardır. Bakterilerde çevreyi algılama sisteminin engellenmesi bunlardan bir tanesi olarak düşünülebilir (Defoirdt vd., 2004).

Bakteriyel patojenler tarafından üretilen sinyal molekülleri, bakteriyel infeksiyonların takibi ve teşhisi için biyolojik işaretleyicilerdir. Çevreyi algılama sinyal moleküllerinin tespiti, bakteriyel infeksiyonları belirlemek için bir araç olarak, çok erken bir safhada daha yararlı olabilir (Boyen vd., 2009).

\section{Alıntılama}

Nurcan N., Kubilay A., Boşgelmez-Tınaz G. 2016. Vibrio anguillarum Suşlarında Çevreyi Algılama Sistemi ve Virülens Faktörlerinin İncelenmesi. Eğirdir Su Ürünleri Fakültesi Dergisi. 12(1), 49-57.

\section{KAYNAKLAR}

Arda, M., 1997. Temel Mikrobiyoloji. Medisan Yayınevi, Medisan Yayın Serisi No:25, 490s. Ankara.

Baskın, H., 2005. Mikroorganizmanın Çevreye Uyumu ve Biyofilm: "Quorum Sensing" (Çoğunluğu Algılama). Klimik 2005 XII. Türk Klinik Mikrobiyoloji ve İnfeksiyon Hastalıkları Kongresi. Dokuz Eylül Üniversitesi Tıp Fakültesi Mikrobiyoloji ve Klinik Mikrobiyoloji Anabilim Dalı, İzmir, 9-10.

Boşgelmez-Tınaz, G., 2003. Quorum Sensing in Gram-Negative Bacteria. Turk J Biol. 27, 85-93.

Bosgelmez-Tinaz, G. "Disruption of Bacterial cell-to-cell communication (Quorum Sensing): A Promising Novel Way to Combat Bacteria-Mediated Diseases". Journal of Marmara University Institute of Health Sciences. 3 (3), 159-163 (2013).

Boyen, F., Eeckhaut, V., Van Immerseel, F., Pasmans, F., Ducatelle, R., Haesebrouck, F., 2009. Quorum sensing in veterinary pathogens: Mechanisms, clinicalim portance and future perspectives. Veterinary Microbiology. 135, 187-195.

Bruhn, J. B, Dalsgaard, I.,Nielsen, K. F., Buchholtz, C., Larsen J. L., Gram L., 2005. Quorum sensing signal molecules (acylatedhomoserine lactones) in Gram-negative fish pathogenic bacteria. Diseases of Aquatic Organisms. (65) 43-52. 
Cha, C.,Gao, P., Chen, Y.C., Shaw, P.D., Farrand, S.K., 1998. Production of acyl homoserine lactone signals by gram-negative plant-associated bacteria. Mol Plant-Microbe Interact. (11) 11191129.

Chu, T.,Ni, C., Zhang, L., Wang Q., Xiao J., Zhang, Y., andLiu, Q., 2015. A quorum sensing-based in vivo expression system and its application in multivalent bacterial vaccine. Microbial Cell Factories. (14), 37

Croxatto, A.,Chalker, V.J., Lauritz, J., Jass, J., Hardman, A., Williams, P., Camara, M., Milton D.L., 2002. VanT, a Homologue of Vibrio harveyi LuxR, Regulates Serine, Metalloprotease, Pigment and Biofilm Production in Vibrio anguillarum. Journal of Bacteriology. 184(6), 1617-1629.

Deepa, S.,Venkateswaran, P., Vinithkumar N. V., Kirubagaran R., 2014. Prevention of Acyle Homoserine Lactone (AHL) mediated biofilm Formation by selected flora of Andaman \& Nicobar Island. Indian Journal of Geo-Marine Sciences. (43),11.

Defoirdt, T.,Boon, N., Bossier, P., Verstraete, W., 2004. Disruption of bacterial quorum sensing: an unexplored strategy to fight infections in aquaculture. Aquaculture. 240, 69-88.

Dong, Y.,Zhang, X., Soo, H.L., Greenberg, P., Zhang, L., 2005. Thetwo-component response regulator PprB modulates quorum-sensing signal production and global gene expression in $P$. aeruginosa. Molecular Microbiology. 56: 1287-1301.

McClean, K.H.,Winson, M.K., Fish, L., Taylor, A., Chhabra, S.R., Camara, M., Daykin, M., Lamb, J.H., Swift, S., Bycroft, B.W., Stewart, G.S.A.B., Williams, P., 1997. Quorum sensing and Chromobacterium violeceum: exploitation of violacein production for the detection of $\mathrm{N}$-acyl homoserine lactones. Microbiology. 143, 3703-3711.

Milton, D. L.,Chalker, V. J., Kirke, D., Hardman, A., Camara, M. and Williams, P. 2001. The Lux $\mathrm{M}$ homologue VanM from Vibrio anguillarum direct sthesynthesis of N-(3-hydroxyhexanoyl) homoserine lactone and $\mathrm{N}$ hexanoyl homoserine lactone. J Bacteriol. 183, 3537-47.

Milton, D.L.,Hardman, A., Camara, M., Chhabra, S.R., Bycroft, B.W., Stewart, G.S.A.B., Williams, P., 1997. Quorumsensing in Vibrio anguillarum: characterization of the vanI/vanR locus and identification of the autoinducer $N$-(3-oxodecanoyl)-l-homoserine lactone. J. Bacteriol. 179, 3004-3012.

Moghaddam, M. M.,Khodi S., Mirhosseini, A. 2014. Quorum Sensing in Bacteria and a Glance on Pseudomonas aeruginosa., Clinical Microbiology: Open Access. 3 (4), ISSN: 2327-5073.

Myszka, K. and Czaczyk K., 2012. N-Acyl homoserine Lactones (AHLs) as Phenotype Control Factors Producedby Gram - Negative Bacteria in Natural Ecosystems. Pol. J. Environ Stud. 21(1), 15-21.

O'Toole G.A. and Kolter R. 1998. Initiation of biofilm formation in Pseudomonas fluorescensWCS365 proceeds via multiple, convergent signalling pathways: a genetic analysis. Molecular Microbiology. 28(3), 449 - 461.

Purohit, A.A., 2013. Acyl homoserine lactone signaling in members of the Vibrionaceae family. University of Tromsøuit.

Rasch, M.,Buch, C., Austin, B., Slierendrecht, W.J., Ekmann, K.S., Larsen, J.L., Johansen, C., Riedel, K., Eberl, L., Givskov, M., Gram, L., 2004. An İnhibitor of Bacterial Quorum Sensing Reduces Mortalities Caused by Vibriosis in Rainbow Trout (Oncorhynchus mykiss, Walbaum). System. Appl. Microbiol. 27, 350-359.

Ravn, L.,Christensen, A.B., Molin, S., Givskov, M., Gram, L., 2001. Methods for acylated homoserine lactones produced by Gram-negative bacteria and their application in studies of AHL-productionk inetics. Journal of Microbiological Methods. 44: 239-251.

Saraçlı, M.A., 2006. "Quorum sensing": mikroorganizmalar iletişim mi kuruyor?. Gülhane Tıp Dergisi. 48(4), 244-250.

Shaw, P.D.,Ping, G., Daly, S.L., Cha, C., Cronan, J.E., JR., Rınehart, K.L., and Farrand, S.K., 1997. Detecting and characterizing $\mathrm{N}$-acyl-homoserine lactone signal molecules by thin-layer chromatography. Proc. Natl. Acad. Sci. USA. 94, 6036-6041. 
Swift, S., Lynch, M.J., Fish, L., Kirke, D.F., Tomas, J.M., Stewart, G.S.A.B. and Williams, P., 1999. Quorum Sensing-Dependent Regulation and Blockade of Exoprotease Production in Aeromonas hydrophila. Infection and Immunity. 67 (10), 5192-5199.

Ulusoy, S., 2007. Yoğun Bakım Ünitelerinden İzole Edilen Pseudomonas aeruginosa Suşlarında NAçil Homoserin Lakton Üretiminin Araştırılması. Doktora Tezi, Süleyman Demirel Üniversitesi, $100 \mathrm{~s}$, Isparta.

Wang, L., 2004. Autoinducer-2 (A1-2) Mediated Quorum Sensing In Escherichia coli., Dissertation submitted to the Faculty of the Graduate School of the University of Maryland, College Park, in partial fulfillment of the requirement forthe degree of Doctor of Philosophy Advisory Committee Thesis.

Ye, J.,Ma, Y., Liu, Q., Zhao, D.L., Wang, Q.Y., Zhang, Y.X., 2008. Regulation of Vibrio alginolyticus virulence by the LuxS quorum-sensing system. Journal of Fish Diseases. 31, 161-169. 